\title{
PENGARUH PENAMBAHAN ALUMINIUM OKSIDA PADA BAHAN BASIS GIGI TIRUAN RESIN AKRILIK POLIMERISASI PANAS TERHADAP KEKERASAN DAN KEKASARAN PERMUKAAN
}

\author{
Mahrizka Desi Ory Lubis, Dwi Tjahyaning Putranti \\ Departemen Prostodonsia, Fakultas Kedokteran Gigi, Universitas Sumatera Utara \\ E-mail: mahrizkalubis@yahoo.com
}

\author{
KATA KUNCI \\ Aluminium Oksida, \\ Kekasaran Permukaan, \\ Kekerasan, Resin Akrilik \\ Polimerisasi Panas
}

\begin{abstract}
ABSTRAK
Pendahuluan : Resin akrilik polimerisasi panas (RAPP) masih menjadi bahan basis gigi tiruan yang paling sering digunakan. RAPP memiliki estetis yang baik, proses pembuatan yang mudah diperbaiki, mudah dalam proses pembuatan, dan harga relatif murah. Meskipun demikian, RAPP memiliki sifat mekanis yang rendah yaitu kekerasan dan sifat fisis yang penting seperti kekasaran permukaan, sehingga diperlukan modifikasi dengan menambahkan bahan penguat berupa aluminium oksida $\left(\mathrm{Al}_{2} \mathrm{O}_{3}\right)$ atau alumina. Tujuan penelitian untuk menganalisis pengaruh penambahan aluminium oksida pada bahan basis gigi tiruan RAPP terhadap kekerasan dan kekasaran permukaan. Metode : Rancangan penelitian ini adalah eksperimental laboratoris dengan 24 sampel berukuran $60 \mathrm{~mm}$ x $10 \mathrm{~mm}$ x $3 \mathrm{~mm}$ dengan konsentrasi kontrol, 7,5\%, 10\%, 15\%. Kekerasan sampel kemudian di uji menggunakan Vickers Hardness Tester dan 24 sampel berukuran 80 $\mathrm{mm}$ x $10 \mathrm{~mm}$ x $3 \mathrm{~mm}$ dengan konsentrasi kontrol, 7,5\%, 10, 15\% untuk kekasaran permukaan kemudian diuji menggunakan Surface Roughness Tester. Data analisis dengan uji T independen Hasil : Nilai kekerasan kelompok kontrol dan ketiga kelompok perlakuan penambahan aluminium oksida 7,5\%,10\%, 15\% berturut-turut adalah 15,551 VHN, 19,339 VHN, 25,505 VHN, dan 30,394 VHN; Sedangkan nilai kekasaran permukaan kelompok kontrol dan ketiga kelompok perlakuan penambahan aluminium oksida 7,5\%, 10\%, 15\% berturut-turut adalah $0,189 \mu \mathrm{m}, 0,221 \mu \mathrm{m}, 0,271 \mu \mathrm{m}$ dan $0,308 \mu \mathrm{m}$. Penambahan bubuk aluminium oksida pada RAPP dapat meningkatkan kekerasan dan kekasaran permukaan secara signifikan $(\mathrm{p}=0,0001$ $(\mathrm{p}<0,05)$, Simpulan : Penambahan aluminium oksida pada bahan basis gigi tiruan resin akrilik polimerisasi panas berpengaruh dalam meningkatkan kekerasan dan meningkatkan kekasaran permukaan yang masih dapat diterima pada konsentrasi $7,5 \%$.
\end{abstract}




\begin{tabular}{l}
\hline KEYWORDS \\
\hline Heat-Polymerized \\
Acrylic Resin, Aluminium \\
Oxide, Hardness, \\
Surface Roughness
\end{tabular}

\section{PENDAHULUAN}

Gigi yang tidak dirawat dapat menjadi rusak sehingga berakibat pada kehilangan gigi. Gigi memiliki fungsi penting bagi setiap orang dan kehilangan gigi apabila tidak diganti dapat mengakibatkan terjadinya perubahan anatomis, fisiologis, maupun fungsional. Kehilangan gigi yang terjadi dapat ditanggulangi dengan pembuatan restorasi berupa gigi tiruan cekat, gigi tiruan sebagian lepasan dan gigi tiruan penuh ${ }^{1}$. Gigi tiruan berada di posisi kedua dalam penggunaan alat yang sering dipakai oleh populasi lansia setelah kacamata ${ }^{2}$. Gigi tiruan bagian dari ilmu prostodontik yang merupakan cabang kedokteran gigi berkaitan dengan pemeliharaan fungsi oral, kenyamanan, penampilan dan kesehatan pasien dengan mengganti gigi yang telah hilang dan jaringan mukosa dengan gigi tiruan $^{3}$. Basis gigi tiruan adalah bagian dari gigi tiruan yang bersandar pada jaringan lunak rongga mulut dan tempat perlekatan anasir gigi tiruan ${ }^{4}$.

Bahan basis gigi tiruan mempunyai sifat biokompatibel, mudah dimanipulasi, mudah dibersihkan, tidak larut dalam cairan rongga mulut dan memiliki kekuatan, kekakuan, kekerasan yang tinggi ${ }^{3}$. Bahan yang digunakan dalam pembuatan basis gigi tiruan terbagi menjadi dua jenis yaitu basis gigi tiruan logam dan non logam. Berdasarkan sifat termalnya, bahan non logam dibagi menjadi termoplastik dan termoset. Contoh 
bahan yang tergolong termoplastik adalah nilon termoplastik. Contoh bahan yang tergolong termoset adalah resin akrilik dan silikon ${ }^{5}$.

Salah satu bahan yang dapat digunakan sebagai bahan basis gigi tiruan adalah resin akrilik atau sering juga disebut sebagai polimetil metakrilat ${ }^{2}$. Resin akrilik polimerisasi panas adalah resin akrilik yang polimerisasinya dengan pemanasan air atau waterbath. Resin akrilik jenis ini tidak memerlukan aktivator kimia dalam proses polimerisasinya, sehingga working time dari resin akrilik ini paling lama apabila dibandingkan dengan resin akrilik swapolimerisasi dan polimerisasi sinar ${ }^{6}$. Sejak tahun 1946, resin akrilik polimerisasi panas (RAPP) sangat sering digunakan sebagai bahan basis gigi tiruan di bidang kedokteran gigi. Resin akrilik polimerisasi panas dipakai karena bahan ini memiliki kelebihan estetika yang baik, teksturnya yang mirip dengan gingiva, mempunyai daya serap air yang relatif rendah, dan perubahan dimensi yang kecil. Bahan basis gigi tiruan RAPP memiliki sifat mekanis yang rendah yaitu kekuatan impak, transversal, dan kekerasan, penghantar termis yang buruk, porositas, menyerap cairan, dan mudah terjadi abrasi pada saat pembersihan. Abrasi pada plat resin akrilik dapat menimbulkan kekasaran pada basis gigi tiruan sehingga menjadi tempat bagi penumpukan debris dan mikroorganisme $e^{7,8}$. Salah satu sifat mekanis dan fisis basis gigi tiruan RAPP adalah kekerasan dan kekasaran permukaan. Nilai kekerasan RAPP adalah 15-18 VHN9. Kekerasan sering digunakan untuk memberikan indikasi kemampuan menahan goresan, menahan tekanan dan ketahanan abrasi suatu bahan. Kekasaran permukaan resin akrilik merupakan sifat penting karena permukaan yang tidak teratur meningkatkan kemungkinan mikroorganisme yang tersisa pada permukaan gigi tiruan setelah dibersihkan. Nilai kekasaran permukaan adalah $0,2 \mu \mathrm{m}^{7,10}$.

Aluminium oksida $\left(\mathrm{Al}_{2} \mathrm{O}_{3}\right)$, yang biasa disebut alumina merupakan salah satu bahan penguat yang digunakan dalam kedokteran gigi. Aluminium bersifat biokompatibel, memiliki ikatan interatomik yang kuat, kekerasan yang tinggi, sifat dielektrik yang sangat baik, refraktori, dan sifat termal yang baik sehingga menimbulkan karakteristik material yang diinginkan, dan juga memperbaiki sifat mekanik. Meskipun berwarna putih, bubuk aluminium oksida tidak memengaruhi penampilan estetis bahan basis gigi tiruan dari $\mathrm{RAPP}^{7,10}$.

Abdulhamed AN dkk ${ }^{11}$ kekerasan meningkat secara signifikan setelah penambahan $\mathrm{Al}_{2} \mathrm{O}_{3}$ pada konsentrasi $5 \%, 7,5 \%, 10 \%$, dan kekasaran permukaan meningkat signifikan pada konsentrasi $10 \%$. Penelitian Vojdani ${ }^{12}$ menunjukkan bahwa terjadi peningkatan yang signifikan pada konsentrasi 2,5\% dan $5 \%$, sedangkan pada kekasaran permukaan tidak ada perbedaan yang signifikan pada konsentrasi $0,5 \%, 1 \%, 2,5 \%$ dan $5 \%$. Tujuan 
penelitian ini adalah untuk mengetahui pengaruh penambahan aluminium oksida pada bahan basis gigi tiruan RAPP terhadap kekerasan dan kekasaran permukaan.

\section{METODE}

Rancangan penelitian yang digunakan adalah penelitian eksperimental laboratoris. Desain yang digunakan pada penelitian ini adalah Post only with control group design. Ukuran model induk dari logam yang akan digunakan untuk uji kekerasan adalah $60 \mathrm{~mm}$ $\mathrm{x} 10 \mathrm{~mm} \quad \mathrm{x} 2.5-3 \mathrm{~mm}$ sesuai ADA specification no.12.1999.7 Ukuran model induk dari logam untuk uji kekasaran permukaan adalah $80 \mathrm{~mm} \times 10 \mathrm{~mm} \times 2.5-$ $3 \mathrm{~mm} .{ }^{7}$ Sampel pada penelitian ini adalah bahan basis gigi tiruan resin akrilik polimerisasi panas tanpa penambahan bahan penguat sebagai kontrol dan bahan basis gigi tiruan resin akrilik polimerisasi panas dengan penambahan bubuk aluminium oksida Beta Diamond Product ukuran partikel $3 \mu \mathrm{m}$ dengan tiga kelompok konsentrasi yang berbeda 7,5\%, 10\% dan 15\%. Bubuk aluminium oksida yang telah ditimbang dicampurkan dengan bubuk RAPP menggunakan pencampuran manual dengan pot porselen dan spatel hingga warna tercampur dengan rata. Bubuk aluminium oksida dan polimer yang sudah merata dicampur dengan cairan resin. Pencampuran bubuk aluminium oksida-polimer dengan cairan RAPP yaitu dengan perbandingan 2:1 berdasarkan berat. Adonan yang telah mencapai fase dough dimasukkan kedalam mold. Besar tekanan pengepresan yang digunakan adalah 1000 psi pada pengepresan pertama dan dilanjutkan dengan tekanan 2200 psi pada pengepresan kedua. Proses kuring dilakukan dengan menggunakan waterbath dengan suhu $70^{\circ} \mathrm{C}$ selama 90 menit dan dilanjutkan dengan suhu $100^{\circ} \mathrm{C}$ selama 30 menit. Sampel yang telah dirapikan dan dipoles direndam di dalam inkubator selama 48 jam pada suhu $37^{\circ} \mathrm{C}$. Sampel kekerasan diuji dengan menggunakan alat Vickers Hardness Tester dengan beban 10gf dengan waktu penekanan selama 10 detik dan sampel kekasaran permukaan diuji dengan menggunakan alat Surface Roughness Tester. Data diperoleh dengan uji $\mathrm{T}$ independen untuk melihat pengaruh kekerasan dan kekasaran permukaan RAPP setelah penambahan aluminium oksida.

\section{HASIL}

Tabel I. Pengaruh Kekerasan Basis Gigi Tiruan Resin Akrilik Polimerisasi Panas Tanpa dan Dengan Penambahan Aluminium Oksida 7,5\%,10\% dan 15\%

\begin{tabular}{|c|c|c|c|}
\hline \multirow{2}{*}{ Kelompok } & \multicolumn{2}{|c|}{$\begin{array}{c}\text { Nilai Kekerasan } \\
\text { (VHN) }\end{array}$} & \multirow{2}{*}{$\mathrm{p}$} \\
\hline & $\mathrm{N}$ & $\bar{X} \pm \mathrm{SD}$ & \\
\hline Tanpa $\mathrm{Al}_{2} \mathrm{O}_{3}$ & 6 & $15,511 \pm 0,276$ & \multirow{2}{*}{$0,0001 *$} \\
\hline $\mathrm{Al}_{2} \mathrm{O}_{3} 7,5 \%$ & 6 & $19,339 \pm 0,538$ & \\
\hline Tanpa $\mathrm{Al}_{2} \mathrm{O}_{3}$ & 6 & $15,511 \pm 0,276$ & \multirow{2}{*}{$0,0001 *$} \\
\hline $\mathrm{Al}_{2} \mathrm{O}_{3} 10 \%$ & 6 & $25,505 \pm 2,508$ & \\
\hline Tanpa $\mathrm{Al}_{2} \mathrm{O}_{3}$ & 6 & $15,511 \pm 0,276$ & \multirow{2}{*}{$0,0001 *$} \\
\hline $\mathrm{Al}_{2} \mathrm{O}_{3} 15 \%$ & 6 & $30,394 \pm 1,065$ & \\
\hline
\end{tabular}

Keterangan : *signifikan $(\mathrm{p}<0,05)$

Tabel 1 menunjukkan nilai kekerasan RAPP tanpa penambahan aluminium oksida adalah 15,511 VHN. Kelompok dengan penambahan aluminium oksida $7,5 \%$, nilai 
kekerasan adalah 19,399 VHN. Kelompok dengan penambahan aluminium oksida $10 \%$ adalah 25,505 VHN. Pada kelompok dengan penambahan aluminium oksida $15 \%$, nilai kekerasan adalah 30,394 VHN. Hasil uji T independen, menunjukkan terdapat pengaruh yang signifikan pada tanpa dan dengan penambahan aluminium oksida 7,5\%, 10\% dan $15 \%$ terhadap kekerasan $(\mathrm{p}=0,0001)$.

Tabel 2. Pengaruh Kekasaran Permukaan Basis Gigi Tiruan Resin Akrilik Polimerisasi Panas Tanpa dan Dengan Penambahan Aluminium Oksida 7,5\%, 10\%

\begin{tabular}{|c|c|c|c|}
\hline \multirow{2}{*}{ Kelompok } & \multicolumn{2}{|c|}{$\begin{array}{l}\text { Nilai Kekasaran } \\
\text { permukaan }(\mu \mathrm{m})\end{array}$} & \multirow{2}{*}{$\mathrm{p}$} \\
\hline & $\mathrm{N}$ & $\bar{X} \pm \mathrm{SD}$ & \\
\hline Tanpa $\mathrm{Al}_{2} \mathrm{O}_{3}$ & 6 & $0,189 \pm 0,009$ & \multirow{2}{*}{$0,0001 *$} \\
\hline $\mathrm{Al}_{2} \mathrm{O}_{3} 7,5 \%$ & 6 & $0,221 \pm 0,012$ & \\
\hline Tanpa $\mathrm{Al}_{2} \mathrm{O}_{3}$ & 6 & $0,189 \pm 0,009$ & \multirow{2}{*}{$0,0001^{*}$} \\
\hline $\mathrm{Al}_{2} \mathrm{O}_{3} 10 \%$ & 6 & $0,271 \pm 0,004$ & \\
\hline Tanpa $\mathrm{Al}_{2} \mathrm{O}_{3}$ & 6 & $0,189 \pm 0,009$ & \multirow{2}{*}{$0,0001 *$} \\
\hline $\mathrm{Al}_{2} \mathrm{O}_{3} 15 \%$ & 6 & $0,308 \pm 0,005$ & \\
\hline
\end{tabular}

Keterangan : *signifikan $(\mathrm{p}<0,05)$

Tabel 2 menunjukkan nilai kekasaran permukaan RAPP tanpa penambahan aluminium oksida adalah 0,189 $\mu \mathrm{m}$. Kelompok dengan penambahan aluminium oksida $7,5 \%$, nilai kekasaran permukaan adalah $0,221 \mu \mathrm{m}$. Kelompok dengan penambahan aluminium oksida $10 \%$ adalah 0,271 $\mu \mathrm{m}$. Pada kelompok dengan penambahan aluminium oksida $15 \%$, nilai kekasaran adalah 0,308 $\mu \mathrm{m}$. Hasil uji $\mathrm{T}$ independen, menunjukkan terdapat pengaruh yang signifikan pada tanpa dan penambahan aluminium oksida 7,5\%, $10 \%$ dan $15 \%$ terhadap kekerasan $(\mathrm{p}=0,0001)$.

PEMBAHASAN
Besarnya kekerasan yang berbeda pada setiap sampel disebabkan oleh faktor-faktor yang memengaruhi proses polimerisasi bahan basis gigi tiruan resin akrilik polimerisasi panas, antara lain teknik pengadukan, kandungan monomer sisa, internal porositas pada matriks resin dan pemolesan ${ }^{13,14}$. Kekerasan pada sampel bahan basis gigi tiruan RAPP yang ditambahkan bubuk aluminium oksida $15 \%$ lebih besar daripada nilai kekerasan pada sampel bahan basis gigi tiruan RAPP tanpa dan dengan penambahan bubuk aluminium oksida 7,5 dan $10 \%$. Hal ini dapat disebabkan karena aluminium oksida memiliki struktur kristal mineral korondum alumina, ikatan interatomik yang kuat, sehingga dapat meningkatkan sifat material yang diinginkan. $\mathrm{Al}_{2} \mathrm{O}_{3}$ memiliki beberapa fase kristalin yaitu fase alfa heksagonal yang paling stabil pada suhu tinggi. $\mathrm{Al}_{2} \mathrm{O}_{3}$ pada fase alfa merupakan oksida terkuat dan paling kaku dari semua keramik oksida. Kekerasan yang tinggi, sifat dielektrik yang baik, refraktori, dan sifat termal yang baik menjadikan $\mathrm{Al}_{2} \mathrm{O}_{3}$ sebagai bahan pilihan yang digunakan untuk berbagai aplikasi. ${ }^{10}$

Berdasarkan hasil tersebut didapat nilai kekasaran permukaan yang bervariasi pada setiap sampel dalam satu kelompok. Hal ini dapat disebabkan karena pada proses pengadukan dilakukan secara manual yaitu dengan menggunakan semen spatel dan pot porselen, sehingga kecepatan dan jumlah pengadukan yang dilakukan tidak dapat 
dikendalikan dengan sempurna, monomer sisa dan porositas yang tidak terlihat juga dapat memengaruhi nilai kekasaran permukaan yang bervariasi. Perbedaan nilai kekasaran permukaan pada tiap sampel dalam kelompok juga dapat disebabkan karena proses pemolesan yang dilakukan secara manual menggunakan kertas pasir, bubuk pumice dan kertas emery membuat tidak ratanya permukaan pada tiap sampel sehingga menyebabkan kekasaran permukaan pada tiap sampel dapat berbeda ${ }^{15}$. Hasil penelitian ini menunjukkan penambahan aluminium oksida pada bahan basis gigi tiruan RAPP dapat meningkatkan kekerasan dan kekasaran permukaan seiring dengan meningkatnya konsentrasi aluminium oksida yang ditambahkan. Hal ini sesuai dengan hasil penelitian Abdulhamed AN $\mathrm{dkk}^{11}$ yang menyatakan bahwa penambahan bubuk aluminium oksida ke dalam bahan basis gigi tiruan RAPP sebanyak 5\%, 7,5\%, dan $10 \%$ dapat meningkatkan kekerasan dan kekasaran permukaan bahan basis gigi tiruan RAPP seiring dengan meningkatnya konsentrasi aluminium oksida yang ditambahkan. Hal ini dapat disebabkan karena jumlah bubuk aluminium oksida pada konsentrasi 7,5\% sebesar 0,255 gr, konsentrasi $10 \%$ sebesar 0,340 gr, dan konsentrasi $15 \%$ sebesar 0,510 gr sehingga semakin tinggi konsentrasi aluminium oksida maka semakin banyak pula bubuk aluminium oksida yang bergabung dengan polimer RAPP. Oleh karena itu, distribusi partikel dari bahan aluminium oksida ke dalam matriks akrilik pada konsentasi tinggi dapat tersebar lebih merata daripada konsentrasi yang lebih kecil ${ }^{11,16}$.

Kekerasan merupakan resistensi suatu bahan terhadap indentasi permanen atau penetrasi. Bahan RAPP mudah tergores, mudah patah dan mudah terjadi keausan karena kekuatan mekanis relatif rendah sedangkan logam tahan terhadap goresan karena relatif keras ${ }^{4}$. Kekerasan yang meningkat dapat diperoleh bila distribusi partikel pengisi aluminium oksida tersebar merata diantara matriks RAPP. Aluminium oksida $\left(\mathrm{Al}_{2} \mathrm{O}_{3}\right)$ yang sering dikenal dengan nama alumina, memiliki beberapa fase kristalin. Fase alpha hexagonal merupakan fase yang paling stabil pada suhu tinggi. Aluminium oksida memiliki ikatan interatomik yang kuat sehingga dapat meningkatkan sifat material yang diinginkan ${ }^{7,10}$. Kekerasan yang rendah menunjukkan bahan yang lunak sehingga menyebabkan bahan basis gigi tiruan RAPP mudah terjadi abrasi, dan begitu juga sebaliknya. Pada implikasi klinis basis gigi tiruan RAPP terjadi abrasi ketika tahap pemeliharaan gigi tiruan yang basisnya dari bahan RAPP pada saat membersihkan gigi tiruan tersebut baik secara mekanis maupun khemis mekanis ${ }^{4,16}$. Kekasaran permukaan meningkat terjadi karena $\mathrm{Al}_{2} \mathrm{O}_{3}$ bertindak sebagai faktor pengganggu dalam integritas matriks polimer, perbedaan dalam jumlah partikel $\mathrm{Al}_{2} \mathrm{O}_{3}$ dengan matriks bahan basis gigi tiruan RAPP, serta perbedaan 
karakteristik struktur mikro dari bahan dan bentuk partikel $\mathrm{Al}_{2} \mathrm{O}_{3}$. Ketika penambahan $\mathrm{Al}_{2} \mathrm{O}_{3}$ ke bahan RAPP dengan konsentrasi yang kecil seperti 7,5\% hanya beberapa partikel akan berhubungan dengan permukaan luar RAPP sehingga pembentukan rongga udara dan kelembaban yang terperangkap sedikit, kemudian pada konsentrasi $7,5 \%$ mengalami peningkatan kekasaran permukaan yaitu memiliki nilai rerata sebesar $0,221 \mu \mathrm{m}$ jika dibandingkan dengan batas toleransi kekasaran permukaan yang dimiliki RAPP sebesar $0,2 \mu \mathrm{m}^{10}$. Penambahan $\mathrm{Al}_{2} \mathrm{O}_{3}$ dengan konsentrasi $10 \%$ dan $15 \%$ akan mengakibatkan lebih banyak partikel yang berhubungan dengan permukaan luar RAPP dan meningkatkan kekasaran permukaan. Gigi tiruan dengan permukaan yang kasar dapat menyebabkan perlekatan plak bakteri. Perlekatan mikroorganisme dapat menyebabkan terjadinya bau mulut, denture stomatitis, dan berbagai keluhan lain yang berhubungan dengan gigi tiruan. Kekasaran permukaan juga memengaruhi estetis, stabilitas warna, dan pembentukan biofilm. Permukaan yang kasar lebih cepat aus dan memiliki koefisien gesek yang lebih tinggi daripada permukaan yang halus. Peningkatan kekasaran permukaan memberikan efek yang merugikan pada estetis gigi tiruan, permukaan RAPP yang halus dapat membantu menahan penumpukan plak, debris dan $\operatorname{stain}^{7,16,17}$.
Penambahan aluminium oksida pada bahan basis gigi tiruan resin akrilik polimerisasi panas berpengaruh dalam meningkatkan kekerasan dan meningkatkan kekasaran permukaan yang masih dapat diterima pada konsentrasi $7,5 \%$.

\section{DAFTAR PUSTAKA}

1. Rawung V, dkk. Uji kekuatan tekan plat resin akrilik polimerisasi panas yang direndam dalam minuman berkabonasi. Jurnal Ilmiah farmasi. 2016; 5(2): 166-70.

2. Raszewski Z, Nowakowska D. Mechanical properties of hot curing acrylic resin after reinforced with different kinds of fibers. International Journal of Biomedical Materials Research 2013; 1(1): 9-13

3. Carr AB, Brown DT. McCracken's removable partial prosthodontics. $12^{\text {th }}$ ed. Missouri: Elsevier, 2011: 2, 103, 106-7.

4. McCabe JF. Anderson's Applied Dental Materials. 6th. Oxford: blackwell, 2008: 4-18, 110-123.

5. Anusavice K, Shen C, Rawls H. Philip's science of dental materials. $12^{\text {th }}$ ed. Philadelphia: Elsevier. 2012: 4, 48-63.

6. Gladwin M, Bagby M. Clinical aspectd of dental materials. $4^{\text {th }}$ ed. Philadelphia: Wolters Kluwer, 2013: 153-5

7. Rassol Jaber M.A. Effect of Aluminium Oxide Addition On The Surface Roughness and Hardness of Acrylic Resin Denture Base. Tikrit journal for dental sciences, 2015; 1: 328.

8. Sitorus Z, Dahar E. Perbaikan sifat fisis dan mekanis resin akrilik polimerisasi panas dengan penambahan serat kaca. Dentika Dent J. 17 (1): 2012: 24-9.

9. Hatrick CD, Eakle WS, Bird WS. Dental material clinical application for dental assistants and dental hygienists. 2th ed. United State of America: Elsevier, 2011: 217-29.

10. Arora P, Singh S.P, Arora P. Effect of Alumina Addition on Properties of Poly methyl methacrylate - A Comprehensive Review. International Journal of Biotech Trends and Technology (IJBTT), 2015: 9(1); 1-7.

11. Abdulhamed AN, Mohammed AM. Evaluation of thermal conductivity of alumina reinforced heat cure acrylic resin and some other properties. J Bagh Coll Dentistry 2010; 22(3): 1-7. 
12. Vojdani M, Bagheri Rafat, Khaledi A.A. Effects of aluminum oxide addition on the flexural strength, surface hardness, and roughness of heat-polymerized acrylic resin. Journal of Dental Sciences, 2012; 7; 238-244

13. Mowade H. The effect of polypropilene fibers in different lengths on some properties of heat-cured acrylic resin processed by autoclave. MDJ 2014; 11(1): 57-61

14. Ahmed MA, Ebrahim MI. Effect of Zirconium Oxide Nano-Fillers Addition on the Flexural Strength, Fractur Toughness, and Hardness of
Heat-Polymerized Acrylic Resin. World J of Nano Science and Engineering 2014; 4: 5057.

15. Pratama A, dkk. Pengaruh kekasaran permukaan terhadap kekuatan tarik baja AISI 4140. J Pendidik Teknik Mesin 2016; 1-9.

16. Craig RG, Powers JM. Restorative dental materials. St.Louis. Mosby, 2010: 79-87.

17. Hilgenberg SP, dkk. Evaluation of surface physical properties of acrylic resin for provisional prothesis. Mat Res 2009; 11(3): 257-60 